\title{
Logical Aspect of Argumentation in Economic
}

\section{Discourse}

Kardovich Irina

Plekhanov Russian University of

Economics

Moscow, Russia

ik_125212@mail.ru
Korobova Ekaterina

Plekhanov Russian University of

Economics

Moscow, Russia

ekkorobova@yandex.ru

\begin{abstract}
The paper focuses on the phenomenon of linguistic argumentation. It covers the results of the research of the logicalcommunicative structure in economic discourse as one of the main components of the text-forming category of argumentation. In the course of the research, the authors carried out an inventory of logical-semantic relations, as well as appropriate means of connection between independent sentences (or groups of sentences) in super phrasal unities (SPU) of the modern economic text. The paper describes in detail the adversative type of logicalsemantic relations and their functions. Whenever possible, the authors compare the results of the present research with the results of their own analysis of scientific-technical texts performed earlier as well as with the data obtained by other researchers who studied logical-semantic relations in literary texts. Seminal works of both Russian and foreign linguists, who carried out their research in the field of linguistic argumentation, laid the foundation for the current research study.
\end{abstract}

Keywords-discourse, text, argumentation, logical-semantic relations, adversative relations, means of connection

\section{INTRODUCTION}

Verbal communication is the basis of the collective experience of world cognition in human society as well as the life of people in all the spheres of their activity. The issues of information exchange, representation of knowledge, its verbal design and methods of transfer have long been the focus of attention of representatives of a number of scientific areas engaged in cognitive processes, including linguistics $[1,2,3]$.

The study of the mind and intellect of man "as a system responsible for all kinds of their activities with information and ensuring the normal course of various mental processes" presupposes scientists' interest in the diverse cognitive abilities of man, such as attention, perception, imagination and others [4]. An equally important role in cognitive development and personality adaptation is played by the ability of argumentation.

Argumentation has been widely studied in various fields of humanitarian knowledge [5, 6, 7, 8]. Unlike most researchers who, interpreting argumentation, emphasize the logical evidentiary) side of this phenomenon [9], the authors consider argumentation as a pragmatic framework for the creation of any speech unit, characterized by a relatively complete meaning, that is, having a certain informative value. In the process of communication people not only pass on to
Konysheva Marina

Russian University of Transport (RUT-MIIT), Institute of Legal

Studies, Moscow, Russia mkonysheva@mail.ru

\author{
Trostina Kira \\ Plekhanov Russian University of \\ Economics \\ Moscow, Russia \\ kiratrostina@mail.ru
}

each other the information about the world around them, but try to impose certain rules of behavior on each

other, emotionally influence the recipient of information, change their beliefs, their behavior in every act of communication. As a result the logical and communicative process of justifying the position of one person for the purpose of its subsequent understanding and acceptance by another person, i.e. argumentation, becomes an integral part of any discourse.

Since the authors will repeatedly resort to the concepts of 'text' and 'discourse', we briefly note our position on these phenomena. We understand discourse as an activity taken in the aggregate of the process and the result, where the process is a verbal activity here and now, and the result is a collection of texts generated in the process of communication .

\section{MATERIALS AND METHODS}

Drawing a parallel between argumentation and its advancement with an idea to prove their theoretical approach many authors treat this phenomenon as an activity aimed at settling the dispute, eliminating the conflict or problem situation under discussion. Such effort or efforts are undertaken to prove the accepted viewpoint, uphold the standpoint, search for a compromise and make it with regard to any pain point.

Thus, the concept of the argumentation is narrowed to a specific form of a discourse activity, to be exact, to a peculiar way of the discourse structure. In our opinion the concept "persuasion" serves as the precise context to compare and determine the status of the proof and the argument.

It is well known that language communication not only confirms or ascertains some event, it also serves to establish mutual understanding (aimed at achieving some result) and bears in itself a tool to influence the interlocutor or the 'communicative partner'. Persuasion and suggestion (i. e. suggestivity) are generally recognized as conventional ways of speech influence.

In the context of the argumentation as a significant element of communication, we are interested, first of all, in the 'persuasion factor' which, unlike 'suggestion factor', is based on reasonable and rational perception of information by the recipient, as well as his/her ability to assess and analyze the information they receive. 
Since the ultimate goal of any argumentation is to persuade the audience to accept the proposed statements, it is equally possible to define argumentation as 'the persuasion tool'.

In our opinion both the ability of the speaker to build argumentation and the resultant perception of this speech by a recipient constitute a basic feature of any form of speech.

Together they determine the human behavior as they are closely connected with communicative activity and the knowledge transfer.

Argumentation is a way to transfer and justify knowledge. Information, coming to the cognizing subject, becomes part of his/her system of knowledge only when, due to argumentation, it passes through their intellectual, sociocultural, ethic and worldview attitudes, and generates preconditions for its interpretation and understanding.

Argumentation, being a universal means of persuasion and the main means of speech influence, is a framework to design and transfer knowledge in the form of mental representation of situations, events, etc. of the real world to pass them on to their addressee.

In other words, any discourse assumes some speech influence; any speech influence in its turn is carried out through persuasion (and/or suggestion); any persuasion is inseparably linked to the argumentation as a logical and communicative process. This communicative process serves to justify a certain point of view so that it can be perceived, understood and (or) accepted by an individual or collective recipient.

The communicative process is a network of different factors, which influence the way information is perceived by the recipient; they are - the purpose of communication, the subject domain of speech activity, the age group of participants, a set of various social, cultural, national, religious and other factors.

Different types of justification are used for argumentation explanation, proof, disproof, definition, denial, assessment, statement, illustration, exemplification and etc.

All the actions mentioned above are special cases of justification of the author's position (opinions, points of view, offers, etc.), i.e. they represent special manifestations of argumentation. As it is revealed above any proof is justification, but not any justification is the proof.

In our opinion, argumentation can be treated in a broader view as a phenomenon permeating all spheres of human activity, starting with everyday communication and ending with scientific disagreements and disputes. It seems to us that argumentation is the basic category that underlies the creation of any speech unit with a relatively complete meaning, and as a result argumentative characteristics are inherent in all the texts but not only in the ones from the spheres of communication that have the task of resolving disputed, conflict situations.

Moreover, we cannot agree with the statement, that "argumentative rhetoric is inherently strictly dialogical", and "argumentative discourse in a monologue speech is an impersonal and dispassionate method of persuasion, unlike a dialogue which vividly expresses rational interests of the participants in the discussion" $[10, \mathrm{p} .66]$. Of course, the dialogue, as a form of communication, significantly reduces misunderstandings in the process of communication, allows quickly adjusting information in accordance with the reaction of the opponent. However, the purpose of any text is to have an effect on the addressee (a reader, listener or interlocutor) in order to influence their system of values and beliefs, their behavior or state of mind in a certain way.

Generating a text built around some concept, the author chooses the language means which, according to his/her idea, will have the fullest impact possible on the recipient. On the other hand these language means should allow the recipient to perceive the text adequately. The text throughout its architectonics and organization, by all the linguistic means used in it should provide the addressee with an opportunity to mold its mental model [11].

A certain language organization of the text gives way to its understanding. In the process of verbal communication, the subject of the speech exerts influence on the recipient with the help of linguistic, paralinguistic and non-linguistic symbolic means. Speech influence is specified by the individual subject goal of the speaker, its potential misinterpretation by the recipient, which might bring about mental rearrangement of its categorical constructs, its effect on the reader's/listener's behavior, transformation of their emotional state and moves of psycho physiological processes. It cannot be carried out without the text category of argumentation which is no less important than other text categories, such as integrity, connectivity, information, and others.

According to the conventional definition, argumentation is represented by several aspects:

- factual, which is information about the facts involved as arguments;

- rhetorical, that is, various forms and styles of speech and emotional impact;

- ethical, meaning moral acceptability or permissibility of arguments;

- logical, implying connectivity and sequence of arguments, and,

- axiological, coupled with a value selection of arguments [10].

The listed components of argumentation mutually complement one another and can vary depending on specific goals, the situation of communication, the vocabulary of the author and a number of other factors.

We distinguish the same components in the textual category of argumentation: factual aspect, i.e. the information outline of the text, supported by its substantive content; logical, represented by a logical sequence of factual information, and rhetorical, aimed at influencing the feelings and emotions of the recipient to produce the necessary convincing effect.

This paper is focused on the logical aspect of argumentation. The material for the study was drawn from the texts of economic discourse, which acts as an important manifestation of scientific knowledge of the modern world. The argumentative arrangement of texts in economic discourse seems to us an interesting and promising material for studying from the cognitive point of view, as a verbal and cogitative 
reflection of one of the main spheres of a modern man's activity.

By tradition, the logical basis of argumentation was analyzed in the context of deduction - induction. Relying on the formal theory of evidence, scholars considered the syllogism as the main model of the argumentation structure. Since syllogisms are characteristic of closed logical systems, their choice as the foundation for the description of the logical basis of verbal communication seems rather artificial.

Defining the nature of argumentation in a wider sense, regarding it as an effective mechanism to achieve the discourse goals, the authors consider it appropriate to transfer the study of the logical aspect of argumentation in particular, and the phenomenon of the argument in the text $\backslash$ discourse in general in the sphere of pragmadialectics, the subject of which is informal argumentation, which has significant differences from the strict induction or deduction [11].

Informal argumentation, also known as presumptive argumentation is devoid of a strict logical framework, explicit deductive or inductive structures and can be referred to the logic of natural speech communication. The main principles, which lie at the heart of the logic of natural speech communication encompass:

- the expediency and effectiveness of a specific argumentation strategy with regard to the context;

- conditional acceptability of the recipient's conclusions, often hypothetical, logically incompletely grounded, based on presumptions and/or assumptions;

- presumptive (variable) nature of the conclusion, connected with the incompleteness or uncertainty of knowledge about the subject of discourse, which subsequently gives the possibility of changing the conclusion of the argumentation with the advent of new information;

- presumptive inference as a basis for argumentation [12].

Despite the fact that this form of inference is neither deduction nor induction, it has a certain logical structure. The authors analyze the logical structure of the texts of economic discourse, which builds the framework of the logical aspect of textual argumentation, and showed its functioning in popular scientific economic texts from The Financial Times.

The present paper describes a system of text-forming logical-semantic relations; appropriate means of connection, joining independent sentences (or groups of sentences) in the super phrasal unity (SPU) of the modern economic text, as well as the functioning of one of the three main types of logicalsemantic relations - adversative relations and their semantic varieties. In accordance with O.I. Moskalskaya's suggestion, we consider the SPU as a mini text endowed with the main regularities of the semantically communicative organization of the text [13]. To prove or overturn the idea about 300 SPUs derived from popular scientific texts of economic discourse have been analyzed.

While doing the research, we carried out an inventory of logical-semantic relations based on the explicit (formally expressed) connection and their means of expression in economic texts. The research was carried out in the following sequence: first we established the logical-semantic relations taking into account the results of similar studies of these relationships in literary texts and the data of our own previous analysis of logical-semantic relations in scientific-technical texts [14], and then we studied the means of expression of each of them.

\section{RESULTS}

Our analysis of the existing classifications of logical-semantic relations based on independent text sentences, our own previous study of the logical-semantic relations in scientifictechnical texts, and the current analysis of the logical aspect of argumentation in economic texts have shown that the specificity of semantic links between independent sentences of the text lies not so much in a large number of basic semantic types, but in a variety of their semantic subtypes.

All logical-semantic relations in economic discourse can be reduced to three main types: connective, adversative and causative, in each of which, in turn, it is possible to distinguish several semantic varieties.

Our list of the main types of logical-semantic relations between independent sentences in economic discourse is presented as follows: connective relations consisting of additive, explanatory and enumerative relations; adversative, including adversative- restrictive, adversative-comparative and adversative-conceding relations; and causative, represented by cause-and-effect and resuming relationships. The complete list of semantic types of relations and their frequency (in percent) in the material of the study is represented in Table 1.

TABLE 1. CLASSIFICATION AND FREQUENCY OF LOGICAL-SEMANTIC RELATIONS IN THE ECONOMIC TEXT

\begin{tabular}{|c|c|c|c|}
\hline $\begin{array}{l}\text { Logical- } \\
\text { semantic types }\end{array}$ & $\begin{array}{l}\text { Varieties of } \\
\text { relations }\end{array}$ & Frequency in \% & Total \% \\
\hline \multirow{3}{*}{ Connective } & Additive & 13.6 & \multirow{3}{*}{27} \\
\hline & Explanatory & 7.9 & \\
\hline & Enumerative & 5.6 & \\
\hline \multirow{3}{*}{ Adversative } & $\begin{array}{l}\text { Adversative - } \\
\text { restrictive }\end{array}$ & 32.6 & \multirow{3}{*}{59.5} \\
\hline & $\begin{array}{l}\text { Adversative- } \\
\text { comparative }\end{array}$ & 13.5 & \\
\hline & $\begin{array}{l}\text { Adversative- } \\
\text { conceding }\end{array}$ & 13.4 & \\
\hline \multirow{2}{*}{ Causative } & Cause-and-effect & 12.3 & \multirow[b]{2}{*}{13.5} \\
\hline & Resuming & 1.1 & \\
\hline \multicolumn{4}{|c|}{$100 \%$} \\
\hline
\end{tabular}

Having carried out an inventory of logical-semantic relations, we defined the means of expressing each of the types and their subtypes.

Studying the means of expressing logical-semantic relations, researchers agree that these are linguistic units specially designed to connect sentences $[15,16]$. The universally recognized means of expressing logical-semantic relations encompass conjunctions and conjunctive adverbs, i.e. words derived from circumstantial and qualitative adverbs, previously defining a verb like thus, therefore. In addition, the means of connection include combinations of prepositions and other parts of speech - nouns, pronouns, known in the literature as "word combinations of a union character" [17]; 
"prepositional phrases" [18]. In the present paper we use the term offered by I.A. Pegova "the equivalent of the conjunctive adverb". I.A. Pegova unites in the equivalence class of conjunctive adverbs combinations of a notional word with a preposition which bear lexical-grammatical meaning similar to conjunctive adverbs and perform the same function, that is, serve to connect independent sentences [19, p.98].

The study of the structure of coherent texts has shown that besides words and phrases, parts of a complex sentence and independent sentences can also convey logical-semantic relations [20].These are the so-called "subordinate sentences", with the basic function to join independent sentences.

For example: This means that..., This is because...

Means of expressing logical-semantic relations in the surveyed material, that is, conjunctions, conjunctive adverbs, equivalents of conjunctive adverbs, parts of a complex sentence (in the examined material there were no independent sentences as means of expressing logical semantic coherence), as well as their frequency are represented in Table 2.

TABLE 2 FREQUENCY OF MEANS OF EXPRESSION OF LOGICAL-SEMANTIC TYPES IN THE ECONOMIC TEXT

\begin{tabular}{|l|c|c|c|c|}
\hline \multirow{2}{*}{$\begin{array}{c}\text { Types of } \\
\text { logical- } \\
\text { semantic } \\
\text { relations }\end{array}$} & \multicolumn{4}{|c|}{ Frequency in \% } \\
\cline { 2 - 5 } Conjunctions & $\begin{array}{c}\text { Conjunctive } \\
\text { adverbs }\end{array}$ & $\begin{array}{c}\text { Equivalents } \\
\text { of } \\
\text { conjunctive } \\
\text { adverbs }\end{array}$ & $\begin{array}{c}\text { Parts of a } \\
\text { complex } \\
\text { sentence }\end{array}$ \\
\hline Connective & 6.6 & 6.7 & 12.4 & 1.1 \\
\hline Adversative & 38.3 & 16.9 & 4.5 & 0 \\
\hline Causative & 10.2 & 0 & 1.1 & 2.2 \\
\hline Subtotal & 55.1 & 23.6 & 18 & 3.3 \\
\hline Total & \multicolumn{5}{|c|}{$100 \%$} \\
\hline
\end{tabular}

We now turn to the description of the adversative type of logical-semantic relations and means of their expression in the economic text. We give the general description of this type, its subtypes and illustrate them on the basis of explicit connection. Wherever possible, we compare the results of our analysis with the data of studies of logical-semantic relations in literary texts from other works, as well as with the results of our own earlier performed analysis of scientific and technical texts.

Adversative relation, as a rule, is considered as the most general relation with the meaning of contrasting connected components, within which several semantic varieties can be distinguished. The analysis of our material and a review of existing classifications made it possible to distinguish within the adversative relations three subtypes: adversative-restrictive, consisting of the relations of clarifying restriction and prohibiting restriction; adversative-comparative, including comparison and opposition, and adversative-concessive relations.

Adversative-restrictive relations
To describe adversative - restrictive relation in a most general way one can define it as a manifestation of logical contradiction between joined sentences. In the "Grammar of the Modern Russian Literary Language" two semantic varieties of restrictive relations are distinguished:

1) prohibiting restriction - connects sentences where there are two phenomena, the second of which interferes with the first one or eliminates its result;

2) clarifying restriction - joins sentences, the second of which denotes a phenomenon that specifies the boundaries and character of the phenomenon indicated in the previous sentence [21, p. 671-672].

In the economic text, similar semantic varieties of adversative-restrictive relations are found. And if prohibiting restriction is represented by occasional examples, the relation of clarifying restriction is very common, which coincides with our data from the scientific-technical text. It is necessary to note that in the literary texts, the occurrence of prohibiting restriction is close to clarifying restriction.

In the economic text, the relation of clarifying restriction is not only the predominant subtype of adversative relations, but also the most frequent logical-semantic relation in general. This relation is conveyed by means of conjunctions: but, yet, however and implicitly. Corresponding to the observations of some researchers, clarifying restriction in scientific texts has a tinge of additional information clarifying and explaining the prior content. In accordance with this, it is typical for sentences connected by clarifying restriction to reproduce in the attached sentence some elements of the preceding content if not all of them. This is carried out by means of lexical repetitions and substitutions. Such semantic reproduction, which clarifies the content of the preceding sentence, and, thereby, restricts it, has also been encountered in our material.

(Example 1) However, one thing is certain: reinventing the practice of management is not going to provide your company with any short-term benefits. But that is the whole point. The road to recovery starts now, and it is therefore a perfect time to put in place the basic changes that will accelerate over time. (The Financial Times, 23/ 02/2010, Bzirkinshaw, J.).

In example 1, the restriction of the content in the first sentence is based on its full semantic reproduction by the word that from the second sentence.

In example 2, the relation of clarifying restriction with the tinge of the complement is introduced by the conjunctive adverb yet.

(Example 2) In practice, few companies were certain enough of the future to comply. Yet some of the Doomsday scenarios about the value of brands in the post-recession world have not come to pass. (The Financial Times, 28/ 04/2010, Gapper, J.).

The conjunction and used to formalize the relation of clarifying restriction sets an illustrative case. In example 3 the conjunction and introduces a sentence that develops the previous statement and simultaneously clarifies its content, limiting it by means of the negative form of the predicate. 
(Example 3) Language and culture are very important for Internet access portals and search services compared with online games. And it is not easy for foreign players to do well in offering such services based on local languages. (The Financial Times, 04/ 05/2010, Harding R., Hille K. and Jung$a, S$.).

In some cases, restriction in the economic text is accompanied by explanation (see example 4).

(Example 4) His talents are summed up in the title of his book Spin: How to Turn the Power of the Press to your Advantage. But although most of his firm's work is for business in trouble, he is probably best known for his celebrity work. (The Financial Times, 17/03/2010, Garrahan, M.).

The relation of prohibiting restriction, presented in literary texts quite widely as restriction based on the inconsistency of the modal plans of the joined sentences and restriction as the elimination of the result of the phenomenon indicated in the previous context, turned out to be not typical of the economic text. We came across only one instance of prohibiting restriction. In the following SPU, the second sentence contains information on the situation that opposes the implementation of the ambitions of Asian Internet companies, which were discussed in the first sentence.

(Example 5) Rakuten's overseas push is part of a growing trend by Asian Internet companies to expand abroad as their domestic growth starts to slow down. But in spite of the ambitions of Asia's young Internet billionaires, cultural barriers and entrenched local competition may prove impossible to overcome. (The Financial Times, 04/ 05/2010, Harding R., Hille K. and Jung-a, S.).

\section{Adversative-comparative relations}

Comparative relation is understood as a relation which establishes the difference between two similar phenomena. The description of a comparative relation is based on the clarification of the relationships in the pair "comparison opposition". There are several points of view on their nature and correlation in research works. Some scholars consider comparison and opposition as different types of relations [22]. Others regard comparison as a specific case of opposition [23], or vice versa - treat opposition as a particular case of comparison [24].

On the whole it is believed that in case of comparison nonantagonistic situations are combined together, and in case of opposition we observe diametrical differences of the correlated situations. In the Grammar of Modern English, the adversative relations between two sentences, the reality of one of which excludes the reality of the other, and the adversative relations under which the truth of the previous sentence is not denied are considered under the general heading "Contrast" [18].

We also rate comparison and opposition among one type of adversative relations-adversative-comparative relations. It is important to underline, that we treat opposition as a case of comparing two situations, with the difference between them which is absolutely antagonistic. The frequency of comparison in economic texts is not high. This coincides with the evidence obtained from literary texts. On the contrary, as the earlier analysis of the scientific-technical text showed, the relation of comparison is quite frequent in it.

Indicators of comparison in the economic text are connectives but and by contrast; while implicit connection is also possible. Below comes an example of comparison.

(Example 6) In many cases, traditional hierarchies are still needed to capture economies of scale or to control risks. But in an increasing number of cases, we can have the economic benefits of large organizations without giving up the human benefits of small ones - freedom, flexibility, motivation and creativity. (The Financial Times, 05/ 11/2008, Malone, T.).

Example 7 illustrates the relation of opposition in the economic text. Like the previously described adversative relation of prohibiting restriction, opposition is not typical of economic discourse and has been found only in a few cases. The following SPU clearly traces the diametrical opposition of correlated situations.

(Example 7) Companies start out on the right track. When things become critical, existing leadership is kicked out, new leaders come in, and the cycle starts again. But not, in the case of a few exceptional businesses. (The Financial Times, 18/ 01/2010, Stern, S.).

\section{Adversative-conceding relations}

Researchers disagree on the content of concession. Some linguists note the similarity of concession with cause-effect relation [25], others emphasize the resemblance of concession with the semantics of adversity [26]. Others regard concession as a synthesis of adversative and cause-effect relations [24]. On the whole, they all keep to the point, that with conceding relations, the content of the attached sentence is opposite to the result expected from the previous one. This phenomenon is called "the effect of deceived expectations". In accordance with this interpretation, concession in most research works is viewed as a subtype within a broader system of adversative relations. In our research study, we adhere to this very understanding of concession.

In economic texts, concession is expressed by means of conjunctions, conjunctive adverbs, equivalent of conjunctive adverbs: but, nevertheless, nevertheless, however, in spite of this. The most frequent means of expressing concession in the economic text is the conjunctive adverb however (example 8). The same connector is also typical of indicating concession in the scientific-technical type of text. We recorded the conjunction nevertheless and the adverb yet in the economic text only once while they are ranked among the most frequent means of expressing concession in literary texts.

(Example 8) Even the founders of Twitter are famous for failing to come up with a way to monetize their ingenious and additive network. However, many companies use the technology to solve 
business challenges, such as finding personnel, improving staff productivity and finding new customers. (The Financial Times, 15/01/2010, Moules,J.)

\section{CONCLUSION}

Our research study of argumentation has brought the following points to the foreground:

1. Argumentation, being a universal way of organizing a discourse to justify a certain point of view of the proponent for the purpose of its perception, understanding, and (or) the adoption by an individual or collective recipient, in terms of logical-communicative organization of economic texts is manifested in three basic types of logical-semantic relations, linking independent sentences of the text among themselves and within the framework of super phrasal unities (SPU) as a whole: connective, adversative and causative. The predominant type of logical-semantic relations in the economic text are adversative relations.

2. Within the three main types of logical-semantic relations functioning in the SPU of economic texts, several semantic groups can be varied: connective relations include additive, explanatory and enumerative relations; adversative relations consist of adversative-restrictive, adversative-comparative and adversative-conceding relations; causative relations are represented by cause-effect and resuming relations.

3. The distinctiveness of logical-semantic relations in the economic text in comparison with similar relations in scientific-technical and literary texts lies in their frequency. In the economic text, the most frequent are adversative relations followed by connective ones. On the contrary, the analysis of the scientific- technical text performed earlier reveals the opposite - the most frequent type of relations in the scientifictechnical text is the connective relation. The specificity of the frequency of relations within the adversative type is the following: the relation of clarifying restriction prevails in the adversative type in economic and scientific-technical texts, while prohibiting restriction occur in few cases (in literary texts these relations occur roughly in equal quantities). The relation of comparison, which does not have a high frequency in economic and literary texts, occurs quite often in scientifictechnical ones.

4. The means of expressing logical-semantic relations in economic texts are represented by conjunctions, conjunctive adverbs, equivalents of conjunctive adverbs, as well as parts of a complex sentence. Of these, the most frequent indicators of relations are conjunctions.

\section{REFERENCES}

[1] Popova Z.D., Sternin I.A. Essays on cognitive linguistics. - Voronezh: "Origins". 2001. - 192 with.

[2] Chomsky N. Language and thinking / N. Khomsky. M., 1972

[3] Maslova V.A. Introduction to cognitive linguistics. - M: Flint. Science, 2008 - 293p.

[4] Kubryakova E.S., Demyankov V.Z. To the problem of mental representations // Questions of cognitive linguistics. - M: Institute of Linguistics; Tambov: Tambov State University. University of. G. R. Derzhavin, 2007 - No. 4 - P. 8-16
[5] Eemeren F.H, Grootendorst R. A systematic theory of argumentation. The pragma-dialected approach. Cambridge: Cambridge University Press. 2004. $216 \mathrm{p}$.

[6] Hitchcock D., Verheij B. (eds): Arguing on the Toulmin Model. New Essays in Argument Analysis and Evaluation. Springer, Dordrecht, 2007, 477 pp.

[7] Baranov A.N. Linguistic theory of argumentation [cognitive approach]: dis. ... Doct. philol. Sciences / ANBaranov. M., 1990. 378 sec.

[8] Perelman Ch., Olbrechts-Tyteca L. The New Rhetoric: A Treatise on Argumentation. Univ. of Notre Dame Press. 1969. 45p.

[9] Brutyan G.A. Argumentation. Yerevan: AN ARM Publishing House. SSR, $1984,105 \mathrm{~s}$.

[10] Philosophical Encyclopedic Dictionary. - Moscow: Soviet Encyclopedia, 1989.

[11] Kulikova O.V. Linguopragmatic grounds of the theory of argumentation (on the material of the English language): dis. ... Doct. philol. Sciences / O.V. Kulikova. - M., 2011. - 367 p.

[12] Walton D.N. Argument Schemes for Presumptive reasoning. NJ, Mahwah: Lawrence Erlbaum Associates, 1996. 232 p.

[13] Moskalskaya O.I. Grammar of the text. - M: High School, 1981 - 183 p.

[14] Kardovich I.K. Connectivity in the scientific and technical text: dis. ... cand. philol. sciences / I.K. Kardovich. M., 1990. - 205 p.

[15] Malchevskaya L.M. Some language means of expressing the connection between sentences: dis. ... cand. philol. sciences / L.M. Malchevskaya. M., 1964. - $184 \mathrm{p}$.

[16] Pavlovskaya V.N. The processes of grammatization of lexical means of connection of sentences in the text: dis. ... cand. philol. sciences / V.N. Pavlovskaya. L., 1982. - 201 p.

[17] Kobrina N.A. Syntactic means of communication between independent sentences in modern English: dis. ... cand. philol. sciences / N.A. Kobrin. - L., 1953. - $308 \mathrm{p}$.

[18] Quirk R., Greenbaum S., Leech G. A University Grammar of English. Moscow, 1982. - 400p.

[19] Pegova I.A. Conjunctive Adverbs and Equivalents of Conjunctive Adverbs as a Means of Connection of Separate Sentences in Modern English (New England Period): dis. ... cand. philol. sciences / I.A. Pegova. M., 1982. - 209 p. [20] Novitskaya I.M. To the syntax of a coherent text (on the material of the German language): Dis. ... cand. philol. sciences. - L., 1973. - 203p.

[21] Grammar of the modern Russian literary language / Ed. N.Yu. Shvedovoi. - Moscow: Nauka, 1970. - 767 p.

[22] Darginavichene I.Yu. Non-union anti-motivations in modern English language. ... cand. philol. sciences / I.Yu. Darginaviciene. - M., 1987. - 143 p.

[23] Kharitonov I.K. Conjunctive-adversarial relations and means of their expression in modern English (in comparison with the modern Ukrainian language): dis. ... cand. philol. sciences / I.K. Kharitonov. - Kiev, 1984. - 212 p.

[24] Lyapon M.V. The semantic structure of a complex sentence and the text (to the typology of intertextual relations). - M.: Science, 1986. - $199 \mathrm{p}$.

[25] Komarova V.V. Conjunction as a means of compressing the supply structure. (On the material of the use of conjunctions of causal semantics in different-system languages): Author's abstract. dis. ... cand. philol. sciences / V.V. Komarova. - Alma-Ata, 1975. - 75 p.

[26] Perelgut N.M. The development of the means of logical semantic connections in the English language: (New England period): dis. ... cand. philol. sciences / NM. Peregut. M., 1983. - 203 p. 